\title{
Re: Colorectal endoscopic submucosal dissection at a low-volume centre
}

Hong Kong Med J 2016;22:512-3

DOI: 10.12809/hkmj164994

To the Editor-I read with interest a recent article titled "Colorectal endoscopic submucosal dissection at a low-volume centre: tips and tricks, and learning curve in a district hospital in Hong Kong" written by Chong et $\mathrm{al}^{1}$ in the June 2016 issue of the Hong Kong Medical Journal. In this series of 71 patients in whom the colonic endoscopic submucosal dissections (ESDs) were performed in an untutored manner, the overall perforation rate and incomplete resection (R1) rate was $15.5 \%$ and $42 \%$, respectively. The authors remarked that similar results had been reported by Berr et al in 2014, ${ }^{2}$ and claimed they were compared favourably with outcomes achieved by expert centres in Japan. Nonetheless, when we read carefully the quoted publication of Saito et al, ${ }^{3}$ the perforation rate by the Japanese endoscopist was only $4.9 \%$, and the curative resection rate was up to $89 \%$. I found it an extremely misleading proclamation by the authors that their ESD results were comparable with that of Japanese experts, while their perforation rate was indeed 3 times higher and complete resection rate was only half that in Saito's series.

It is an undeniable fact that ESD is a new minimally invasive treatment for large adenomatous (including lateral spreading type) colonic polyps. The authors should not encourage performing the procedure without supervision. There are several issues that should raise concern:

(1) There was no mention of any ethics approval application in the article. Did patients undergoing this procedure know that their endoscopist had not undergone formal training beforehand? Did the first cohort of patients know their ESD would be performed on an experimental basis and not under any supervision?

(2) In 2009, there were already a reasonable number of endoscopists in Hong Kong with experience in ESD. Why did the authors insist on starting this procedure in an untutored manner?

(3) In the article, the authors reported that the endoscopist had attended a workshop in which he gained hands-on experience of ESD by attempting the procedure in a porcine model. It is common knowledge that most of these workshops held by various training centres are by no means a legitimate reason to start a new high-risk procedure by the novice. They are just educational programmes that aim to enhance the knowledge and interest of delegates in new therapeutic technology. The authors' recommendation to start performing a novel invasive procedure without formal training and expert coaching goes against the current trend of accreditation and credentialing in advanced endoscopy. ${ }^{4}$

Enders KW Ng *, FRCSEd, MD (CUHK)

Department of Surgery, The Chinese University of Hong Kong, Prince of Wales Hospital, Shatin, Hong Kong

* Corresponding author: endersng@surgery.cuhk.edu.hk

\section{References}

1. Chong DH, Poon CM, Leong HT. Colorectal endoscopic submucosal dissection at a low-volume centre: tips and tricks, and learning curve in a district hospital in Hong Kong. Hong Kong Med J 2016;22:256-62.

2. Berr F, Wagner A, Kiesslich T, Friesenbichler P, Neureiter D. Untutored learning curve to establish endoscopic submucosal dissection on competence level. Digestion 2014;89:184-93.

3. Saito Y, Uraoka T, Yamaguchi Y, et al. A prospective, multicenter study of 1111 colorectal endoscopic submucosal dissections (with video). Gastrointest Endosc 2010;72:1217-25.

4. Kumta NA, Yamamoto H, Haber GB. Training the next generation of Western endoscopists in endoscopic submucosal dissection. Gastrointest Endosc 2014;80:680-3.

\section{Authors' reply}

To the Editor-An untutored approach to acquire a new technique is the worst choice yet it is inevitable when "a reasonable number of endoscopists" with expertise in endoscopic submucosal dissection (ESD) is not available. "Formal training" in terms of workshop attendance and animal model practice was the best available training while "expert coaching" remained a utopia in Hong Kong before 2009 when there was no single endoscopist who had performed more than 35 colorectal ESDs. The only published data on colorectal ESD in Hong Kong was derived from 65 patients over a 4-year period, from 2010 to 2013 , and reflected the absence of an expert prior to 2010. ${ }^{1}$ As stated in our paper, "The low case volume and the absence of expertise in western countries leads to the development of untutored colorectal ESD when it is impossible to have a step-up approach in ESD training starting from the stomach before 
proceeding to colon."

The untutored approach is not an experimental trial that requires ethical approval. Both the endoscopist and the patient should be well prepared with facilities available before the start of such a new procedure, and patient safety is a top priority. From the endoscopist's perspective, acquirement of knowledge and technique through workshop attendance, continual animal model hands-on training, clinical observation at an expert centre, and a low threshold of conversion to hybrid technique (endoscopic mucosal resection) for unfavourable lesions should be ensured. This was reflected in our reported first learning curve where $57.7 \%$ of patients needed to undergo the hybrid technique for en-bloc resection. From the patient's perspective, careful patient selection, full explanation of the traditional and new treatment option with informed consent for immediate conversion to traditional laparoscopic colectomy if required should be offered. This is why ESD should be performed in an operating theatre with an anaesthetist in attendance. It can allow one-stop treatment in case of failure to remove the lesion or if complications arise. In our case series, two patients were cured by one-stop treatment and made an uneventful recovery.

Perforation is considered the major morbidity in ESD. Saito et $\mathrm{al}^{3}$ quoted an immediate perforation in $54(4.9 \%)$ patients and delayed perforation in four $(0.4 \%)$ with an overall perforation rate of $5.3 \%$ in a multicentre study of 1111 patients from 1998 to $2008 .^{3}$ If we look at an earlier paper by Taku et $\mathrm{al}^{4}$ on iatrogenic colonoscopic perforation in Japan from 1999 to 2003, ESD perforation occurred in six out of 43 patients at a perforation rate of $14 \%$ and is comparable with our series. In our paper we concluded "Untutored colorectal ESD at a low-volume centre was an option in the absence of enough experts to supervise the procedure... When more endoscopists have gained experience in colorectal ESD, a structured training programme with accreditation can be established." Seven years after we started the procedure, structured guidelines for management of early gastrointestinal (GI) cancers are finally available. ${ }^{5}$ In the section on endoscopist's credentialing process, structured training in ESD includes (1) attendance at workshops dedicated to early GI cancer training; (2) animal model hands-on training; (3) dedicated centre observation; and (4) minimal 10 cases of successful and non-complicated ESD under supervision before being independent, preferably started from the rectum. When untutored colorectal ESD will cease in Hong Kong, it will remain an option in other countries with insufficient experienced supervisors.

\section{Deon HM Chong, FRCSEd \\ CM Poon, FRCSEd \\ HT Leong *, FRCSEd}

Department of Surgery, North District Hospital, Sheung Shui, Hong Kong

* Corresponding author: lamyn@ha.org.hk

\section{References}

1. Hon SS, Ng SS, Wong TC, et al. Endoscopic submucosal dissection vs laparoscopic colorectal resection for early colorectal epithelial neoplasia. World J Gastrointest Endosc 2015;7:1243-9.

2. Chong DH, Poon CM, Leong HT. Colorectal endoscopic submucosal dissection at a low-volume centre: tips and tricks, and learning curve in a district hospital in Hong Kong. Hong Kong Med J 2016;22:256-62.

3. Saito Y, Uraoka T, Yamaguchi Y, et al. A prospective, multicenter study of 1111 colorectal endoscopic submucosal dissections (with video). Gastrointest Endosc 2010;72:1217-25

4. Taku K, Sano Y, Fu KI, et al. Iatrogenic perforation associated with therapeutic colonoscopy: a multicenter study in Japan. J Gastroenterol Hepatol 2007;22:1409-14.

5. Task Force on Endoscopic Diagnosis and Management of Early GI Cancers, Hospital Authority. Guidelines on endoscopic diagnosis and management of early GI cancers and guidelines on handling and pathological examination of endoscopic submucosal dissection (ESD) specimens for GI neoplastic lesion. Hong Kong: Hospital Authority; 2015. 